\title{
Renin-angiotensin-aldosterone system in the elderly: rational use of aliskiren in managing hypertension
}

\author{
Karl Andersen \\ Department of Medicine, Division \\ of Cardiology, Landspitali University \\ Hospital, University of Iceland, \\ Reykjavik, Iceland
}

\begin{abstract}
The overall purpose of hypertension treatment is 2-fold. First, patients often have symptoms that are related to their high blood pressure and although subtle in many instances may be improved dramatically by blood pressure control. The main reason for blood pressure treatment, however, is to reduce the burden of cardiovascular complications and end organ damage related to the condition. This may be considered the ultimate goal of blood pressure treatment. In this respect, actual blood pressure measurements may be seen as surrogate end points as the organ protective effects of two antihypertensive agents may differ significantly even though their blood pressure lowering effects are similar. Thus beta-blockers, once seen as first-line treatment of hypertension for most patients, now are considered as third- or fourthline agents according to the latest NICE guidelines (National Institute for Health and Clinical Excellence, www.nice.org.uk/CG034). On the other hand, agents that inhibit the activity of the renin-angiotensin-aldosterone system (RAAS) system are being established as safe, effective and end organ protective in numerous clinical trials, resulting in their general acceptance as first-line treatment in most patients with stage 2 hypertension. This shift in emphasis from betablockers and thiazide diuretics is supported by numerous clinical trials and has proven safe and well tolerated by patients. The impact of this paradigm shift will have to be established in future long-term randomized clinical trials. The optimal combination treatment with respect to end organ protection has yet to be determined. Most combinations will include either a RAAS active agent and calcium channel blocker or two separate RAAS active agents working at different levels of the cascade. In this respect direct renin inhibitors and angiotensin receptor blockers seem particularly promising but the concept awaits evaluation in upcoming randomized clinical trials. Although safety data from the randomized clinical trials to date have been promising, we still lack data on the long-term effect of aliskiren on mortality and there still are patient groups where the safety of aliskiren is unexplored.
\end{abstract}

Keywords: aliskiren, elderly, hypertension, renin-angiotensin-aldosterone system

\section{Introduction}

High blood pressure is a major risk factor for stroke, myocardial infarction, heart failure, peripheral artery disease and renal failure. ${ }^{1-3}$ The global prevalence of hypertension is believed to be $25 \%$ to $30 \%$ in the adult population and is steadily increasing in western societies. ${ }^{4-6}$ Among the elderly ( $>65$ years) the prevalence of hypertension is even higher, reaching $50 \%$ to $70 \%{ }^{7}$ and is an increasing public health concern. ${ }^{8}$ The condition confers a 3- to 4-fold increased risk of cardiovascular disease and renal failure and is associated with declining cognitive function among the affected. ${ }^{9}$

There is a continuous independent relationship between elevated systolic blood pressure (SBP) and diastolic blood pressure (DBP) and stroke and cardiovascular mortality for all age groups. The mortality risk is doubled for every $20 \mathrm{mmHg}$ rise in SBP and $10 \mathrm{mmHg}$ rise in DBP from the level of $115 / 75 \mathrm{mmHg} .{ }^{10}$ Based on the 
steadily increasing proportion of elderly in the population, it can be predicted that cardiovascular and renal complications of high blood pressure will increase even further in the coming decades unless appropriate preventive measures are taken.

In an attempt to attenuate the dire complications of hypertension, clinicians are faced with an array of antihypertensive agents. In many instances, the older generic drugs have been found as effective for blood pressure lowering as the newly developed antihypertensive agents. However, only recently randomized clinical trials have provided insight into the relative efficacy of these agents to confer end organ protection which may be seen as the ultimate goal of blood pressure treatment. Selection of antihypertensive treatment needs to be based on the presumed clinical benefit that may be obtained for different patient groups. In this context health care providers will increasingly rely on randomized clinical trials to tailor treatment alternatives to each individual patient. This review will focus on treatment of hypertension in the elderly population with special reference to the value of agents acting on the renin-angiotensin-aldosterone system (RAAS) including the direct renin inhibitor (DRI) aliskiren.

\section{Hypertension in the elderly}

With advancing age the aorta and medium size arterioles become calcified and lose elasticity. This process is dependent on age-related changes of elastin fibres in the media, proliferation of collagen and deposition of calcium. The resulting arteriosclerosis causes a rise in peripheral vascular resistance and elevated SBP but also a fall in DBP and consequently, a high pulse pressure. The changes in the vascular tree that occur with advancing age are rather complicated and include, apart from calcification, humoral changes and vascular hypertrophy. This results in a continuous rise in SBP throughout adult life, whereas DBP peaks at about 60 years of age and declines thereafter. The resulting rise in pulse pressure with advancing age has been used as a predictor of adverse cardiovascular outcome. ${ }^{11,12}$

Aortic stiffness, measured by carotid-femoral pulse wave velocity, increases the risk of cardiovascular mortality, coronary events and fatal strokes among the elderly. ${ }^{13,14}$ This risk factor becomes more important in patients over 50 years of age. ${ }^{11}$ The proportion of elderly subjects is steadily growing in industrialized countries and is expected to reach a quarter of the US population by year $2035 .{ }^{15}$ The prevalence of isolated systolic hypertension in this age group is over $65 \%{ }^{16}$ and the lifetime risk of developing hypertension exceeds $90 \%$. The importance of blood pressure control in this age group has been confirmed by several interventional trials. ${ }^{17-19}$ In spite of these facts, only $20 \%$ of elderly hypertensives have blood pressure controlled to values below 140/90 $\mathrm{mmHg}$.

This may have a serious impact in the overall health of elderly people causing cardiovascular disease, heart failure, stroke, renal failure and reduced quality of life.

\section{The RAAS in hypertension}

The RAAS plays a central role in the regulation of blood pressure (Figure 1). Renin, an aspartic protease, is generated and released by the juxtaglomerular cells in the kidney. It has one known substrate, angiotensinogen, and catalyzes the conversion of angiotensinogen to angiotensin I (Ang I) in the rate limiting step of the cascade. Formation of Ang I is favored by a 5000 -fold concentration gradient. The decapeptide Ang I is then converted to the octapeptide angiotensin II (Ang II) by angiotensin-converting enzyme (ACE). The Ang II thus formed acts on receptors of Ang II (AT-1 receptors) to raise blood pressure through several mechanisms. Most importantly, Ang II is a powerful vasoconstrictor, it stimulates the release of aldosterone from the adrenal cortex and subsequently leads to sodium reabsorbtion in the kidney and catecholamine release from the adrenal medulla. Hypertension can be caused by pathologic activation of the RAAS, leading to salt and water reabsorbtion, vasoconstriction and increased catecholamine release.

Recently, the discovery of the (pro)renin receptor has changed our understanding of how the RAAS system is involved in end organ damage. ${ }^{20}$ Pro-renin is a precursor to renin which has a 43 amino acid N-terminus overlying the enzymatic cleft of the renin molecule, thus rendering it inactive. Pro-renin is much more abundant than renin in the circulation and its concentration is especially high in diabetics. Pro-renin can be activated both by proteolytic and nonproteolytic pathways. The proteolytic pathway takes place in the juxtaglomerular apparatus in the kidney where the 43 amino acid $\mathrm{N}$-terminus is removed and leaves the active renin molecule. Non-proteolytic activation of pro-renin takes place by binding to the (pro)renin receptor. Pro-renin thereby becomes enzymatically active without losing its $\mathrm{N}$-terminus and this binding increases its emzymatic activity 4 - to 5 -fold. The activation of pro-renin leads to Ang II production locally at the cell surface where it is in close vicinity with ACE and the AT-1 receptor. At the tissue level renin and pro-renin also have physiologic effects through the (pro)renin receptor that are completely independent of Ang II production. Intracellular signaling pathways cause upregulation of pro-fibrotic mediators that lead to contractility disturbances, hypertrophy, 


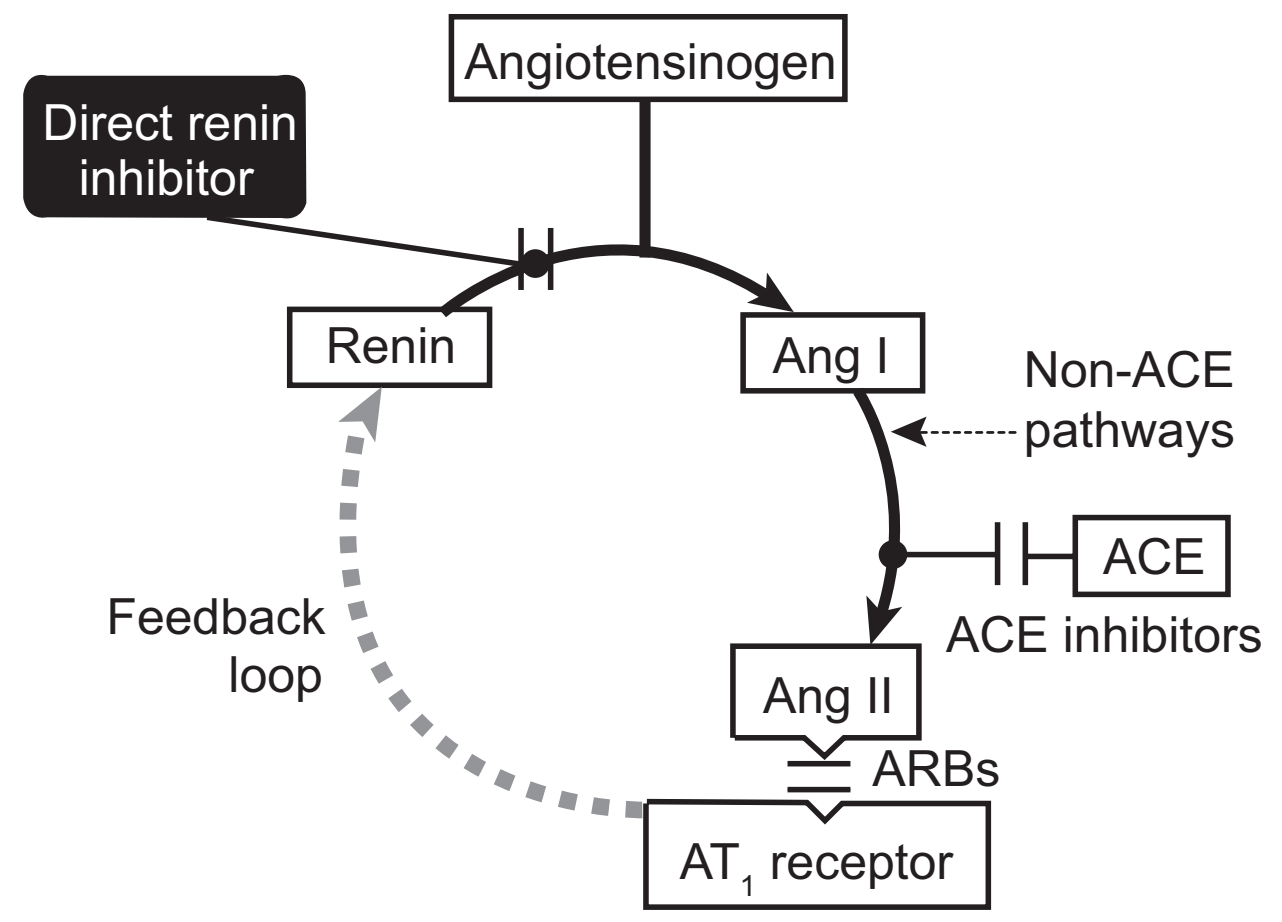

Figure I The renin-angiotensin-aldosterone system and points of pharmacological intervention.

Abbreviations: ACE, angiotensin converting enzyme; Ang I, angiotensin I; Ang II, angiotensin II; ARB, angiotensin receptor blocker; ATI, angiotensin type I receptor.

fibrosis and apoptosis. This is a potential second target for control of the RAAS with renin inhibitors that might lead to organ protection beyond the blood pressure lowering effects achieved by ACE-inhibitors (ACE-I) and angiotensin receptor blockers (ARBs).

Inhibition of the RAAS has long been the target of pharmacological blood pressure regulation. Inhibitors of the ACE reduce the production of Ang II and have been proven to be effective blood pressure lowering agents. Their effectiveness is, however, hampered by the ACE-independent pathways of chymases and dipeptidases that are found in end organs such as the heart, blood vessels and kidneys. Thus, Ang II can still be produced by these pathways in spite of effective ACE-I. In addition, ACE-I often have side affects including cough that is thought to result from the accumulation of bradykinin and substance $\mathrm{P}$ due to the blockage of their breakdown.

Another target of RAAS inhibition is blockade of the AT-1 receptor by ARBs. Other receptors of Ang II such as AT-2 and AT-4 are not affected, but the clinical effect of their unopposed stimulation is not fully understood. This may include inflammatory and fibrotic responses leading to vascular damage and left ventricular hypertrophy. Both ACE-I and ARBs attenuate the negative feedback loop of Ang II on renin production and thus increase both renin concentration and plasma renin activity.
Direct renin inhibition (DRI) is a new concept in the treatment of hypertension. ${ }^{21}$ The prototype compound aliskiren is a small-molecular-weight, orally active, non-peptide that has high affinity for the active site on the renin molecule. Although the bioavailability of aliskiren is rather low after oral administration (2.5\%), its high affinity and specificity for the renin molecule and plasma half-life of 24 to 36 hours makes it suitable for once-daily dosage. Similar to other blockers of the RAAS and thiazide diuretics, aliskiren increases plasma renin concentration (PRC). However, in contrast to other drug classes acting on the RAAS, the plasma renin activity (PRA) is effectively blocked by aliskiren. The potential benefit of DRI on end organ protection might also be related to Ang II independent effects of renin on the tissue level. Thus DRIs might not only inhibit the conversion of angiotensin to Ang I, both in the circulation and tissue level, but also blunt intracellular pathways of end organ damage induced directly by receptor bound (pro)renin. ${ }^{22}$

\section{Treatment of hypertension in the elderly}

Although previously thought to be of limited value or even harmful, it has now become evident from several randomized clinical trials and meta-analyses that treatment of hypertension in the elderly may reduce stroke and heart failure rates and even have a mortality effect. ${ }^{23,24}$ The main 
goal of hypertension treatment is to reduce or prevent cardiovascular and renal disease. There is especially high risk for such complications in the elderly population. The increased risk of debilitating stroke caused by high SBP is a major concern among elderly hypertensives and needs to be treated aggressively, as stroke has a major impact on quality of life and life expectancy of these patients..$^{25-27}$ According to current ESH-ESC Guidelines on management of hypertension ${ }^{28}$ and several clinical trials, elderly patients benefit from antihypertensive therapy in terms of reduced cardiovascular morbidity ${ }^{18,29-32}$ and mortality. ${ }^{24}$

Although elevated blood pressure has been the subject of intensive clinical and experimental studies through the last 5 decades and an arsenal of effective and safe antihypertensive medication is available, we still are far from achieving acceptable control rates. The results of the Euroaspire III study presented at the European Congress of Cardiology in Munich $2008^{33}$ showed that in spite of increased use of antihypertensive medication, the control rate of hypertension had not improved and $61 \%$ of patients were above the therapeutic target of $140 / 90 \mathrm{mmHg}$.

\section{Non-pharmacological treatment}

Life style modification with weight loss and reduced salt intake are of particular value in the elderly because most of these patients are obese and salt sensitive. In the Trial of Nonpharmacologic Interventions in the Elderly (TONE), sodium intake was reduced to $80 \mathrm{mmol}(2 \mathrm{~g})$ per day and resulted in a modest reduction in SBP and DBP and $40 \%$ of the treated patients were able to discontinue previous medication. ${ }^{34}$ In this study, additional blood pressure lowering was seen when weight loss was added to salt restriction. Life style modification in the elderly should also encourage physical activity.

\section{Pharmacological treatment}

Pharmacological treatment of hypertension in the elderly follows the same general principles that are laid out in the current guidelines ${ }^{6,28}$ and taking into consideration individual compelling indications for specific drug classes. ${ }^{35-39}$ However, in the elderly population these recommendations are based on a limited number of clinical trials. Bearing in mind the increased variability in blood pressure among elderly hypertensives, their reduced cardiovascular sensitivity to catecholamine stimulation and tendency to postural hypotension, care should be taken to initiate drug therapy with low doses and titrate up to effective doses according to individual response. As with hypertension in general, the elderly are likely to need two or more different medications in order to control their blood pressure.

Although it is no longer disputed that effective blood pressure treatment leads to considerable reduction in cardiovascular disease in general and stroke risk in particular, there is still uncertainty of whether specific classes of blood pressure lowering agents confer a greater benefit than others in end organ protection. ${ }^{40}$

\section{Placebo-controlled trials}

In the Swedish Trial in Old Patients with Hypertension ${ }^{29}$ 1627 hypertensive patients 70 to 84 years of age were randomized in a double blind fashion to treatment with beta-blockers or thiazide diuretic vs placebo. The entry blood pressure criteria were SBP between 180 and $230 \mathrm{mmHg}$ with a diastolic pressure of at least $90 \mathrm{mmHg}$, or a DBP between 105 and $120 \mathrm{mmHg}$ irrespective of the systolic pressure. The mean difference in blood pressure levels between treatment arms was 19.5/8.1 mmHg after an average of 25 months of treatment. In this trial the SBP lowering effect of the thiazide was more pronounced than that of the beta-blockers. The primary end point of stroke, myocardial infarction and cardiovascular death was significantly reduced by $38 \%$ $(\mathrm{p}=0.0031)$, stroke rate was reduced by $45 \%(\mathrm{p}=0.0081)$ and there was also a significant reduction in death rate among the actively treated patients. This study established that morbidity and mortality reductions can be achieved in elderly hypertensives with active blood pressure lowering treatment based on beta-blockers or thiazide diuretics.

The European Working Party on High Blood Pressure in the Elderly trial ${ }^{41}$ was a double-blind, placebo controlled trial of diuretic based (hydrochlorothiazide + triamterene) treatment vs placebo in hypertensive subjects, 60 years or older with entry blood pressure levels of 160 to $239 \mathrm{mmHg}$ systolic and 90 to $119 \mathrm{mmHg}$ diastolic. Methyldopa could be added to the active treatment group in case of suboptimal blood pressure control. The results showed no significant reduction in total mortality by active treatment $(9 \%, \mathrm{p}=0.41)$, but a significant reduction in cardiovascular mortality $(27 \%$, $\mathrm{p}=0.037$ ) that was mainly driven by a $38 \%$ reduction in cardiac mortality $(\mathrm{p}=0.036)$.

The Systolic Hypertension in the Elderly Program (SHEP) ${ }^{18}$ was a clinical trial where 4736 elderly subjects with stage 2 isolated systolic hypertension (systolic $\geq 160 \mathrm{mmHg}$, diastolic $<90 \mathrm{mmHg}$ ) were randomized to treatment with a thiazide type diuretic (chlorthalidone) or placebo. In the active treatment arm atenolol, resperine and hydralazine could be added to achieve blood pressure control. SBP was 
lower in the treatment group $(143 \mathrm{mmHg}$ ) than the control group $(155 \mathrm{mmHg})$ and the primary end point of stroke was significantly reduced by $36 \%(\mathrm{p}=0.0003)$, heart failure by $49 \%$ and coronary events by $27 \%$. The treatment was well tolerated. This was a landmark trial that showed that blood pressure lowering in elderly patients was not only safe, but also effective in reducing clinical end points.

The placebo-controlled randomized HYVET trial ${ }^{24}$ studied 3845 hypertensive subjects over 80 years of age with a sustained SBP of $160 \mathrm{mmHg}$ or greater. Treatment was initiated with a thiazide (indapamide sustained release $1.5 \mathrm{mg} /$ day) and an ACE-I (perindopril 2-4 mg/day) added if needed for blood pressure control ( $<150 / 80 \mathrm{mmHg})$. The primary end point was fatal and non-fatal stroke with a median follow-up period of 1.8 years. The study was stopped prematurely by the data safety monitoring board for ethical reasons. The results showed a $30 \%$ reduction in the primary end point that was of borderline statistical significance $(\mathrm{p}=0.06)$. However, there was a convincing $39 \%$ reduction in stroke mortality $(\mathrm{p}=0.05)$, a $21 \%$ reduction in all cause mortality $(\mathrm{p}=0.02)$ and a $64 \%$ reduction in heart failure $(\mathrm{p}<0.001)$ at follow-up indicating that this approach to treat hypertensive patients 80 years or older with a thiazide diuretic, allowing optional combination with an ACE-I is not only safe, but also lowers stroke rate, heart failure and all cause mortality and thus confers a significant clinical benefit to this patient group.

These placebo-controlled trials confirm the efficacy of thiazides alone or in combinations for end organ protection in elderly hypertensives. This is supported by a meta-analysis looking at 18 placebo controlled trials of elderly hypertensive patients where diuretics were found to reduce stroke risk by $51 \%$ (relative risk [RR] $0.49,95 \%$ confidence interval CI $0.39-0.62$ ) and beta-blockers by $29 \%$ (RR $0.71,95 \%$ CI $0.59-0.86$ ) compared to placebo. ${ }^{42}$

The Systolic Hypertension in Europe (Syst-Eur) study, ${ }^{31}$ elderly patients with systolic hypertension $\geq 160 \mathrm{mmHg}$, but diastolic $<95 \mathrm{mmHg}$, were randomized to the dihydropyridine calcium channel blocker nitrendipine or placebo. The study was stopped prematurely by the data safety monitoring board because of a highly significant $(p=0.003) 43 \%$ reduction in stroke by the calcium channel blocker. More surprisingly, there was also a highly significant $55 \%$ reduction in dementia by the calcium channel blocker.

A large Chinese study of hypertensive patients ${ }^{32} 60$ years or older compared the dihydropyridine calcium channel blocker nitrendipine 10 to $40 \mathrm{mg} /$ day, with addition of the ACE-I captopril 12.5 to $50 \mathrm{mg}$ /day or hydrochlorothiazide
12.5 to $50 \mathrm{mg} /$ day for adequate blood pressure control against placebo. After 2 years of follow-up the blood pressure difference between placebo and active treatment groups was 9.1/3.2 $\mathrm{mmHg}$ which resulted in a significant reduction in stroke rate $(38 \%, \mathrm{p}=0.01)$, all cause mortality $(39 \%, \mathrm{p}=0.003)$, cardiovascular mortality $(39 \%, \mathrm{p}=0.03)$, stroke mortality $(58 \%$, $\mathrm{p}=0.02)$ and all cardiovascular end points $(37 \%, \mathrm{p}=0.004)$ in the active treatment group as compared to placebo.

The Study on Cognition and Prognosis in the Elderly (SCOPE) $)^{43}$ was a randomized, study including 4964 patients 70 to 89 years of age with stage 2 hypertension (systolic 160-179 mmHg and or diastolic 90-99 mmHg) and a Mini Mental State Examination (MMSE) score of 24 or higher. Patients were randomized to receive the angiotensin receptor blocker candesartan or placebo with open label antihypertensive treatment added as needed for blood pressure control. After a mean follow-up of 3.7 years the primary composite end point of cardiovascular death, non-fatal stroke, and non-fatal myocardial infarction was not significantly different between treatment groups. However, non-fatal stroke was reduced by $27.8 \%(\mathrm{p}=0.04)$ in the candesartan group and similarly, all cause stroke was reduced by $23.6 \%(p=0.056)$. No difference was found between groups in myocardial infarction and cardiovascular mortality. There was no difference between treatment groups in the outcome of MMSE. Blood pressure was 3.2/1.6 mmHg lower in the candesartan group.

A remarkably high rate of blood pressure control was achieved in a randomized, placebo controlled trial using perindopril $2 \mathrm{mg}$ combined with indapamide $0.625 \mathrm{mg}$ as active treatment during 1 year among elderly patients with essential or isolated systolic hypertension. ${ }^{44}$ The mean blood pressure reduction was $23 / 13.3 \mathrm{mmHg}$ and $79.8 \%$ of the patients achieved blood pressure control with this low dose combination treatment, which was well tolerated and equally effective in elderly (65-74 years) as in very elderly (75-85 years) patients.

These placebo-controlled trials of elderly patients with stage 2 and 3 hypertension confirm that treatment of high blood pressure confers a clear benefit in reducing cardiovascular mortality and morbidity in this age group. The agents most effective in this respect seem to be thiazide diuretics, calcium channel blockers and possibly ACE-I and ARBs although the data available for the last two classes are limited.

\section{Active comparator trials}

The Swedish Trial in Old Patients with Hypertension-2 (STOP-2) study ${ }^{45}$ aimed to compare the effects of conventional 
and newer antihypertensive drugs on cardiovascular mortality and morbidity in elderly patients. This was a prospective, randomized trial including 6614 patients, 70 to 84 years of age with $\mathrm{SBP} \geq 180 \mathrm{mmHg}$ and/or DBP $\geq 105 \mathrm{mmHg}$. The treatement in the conventional group was made up of beta-blockers (atenolol $50 \mathrm{mg}$, metoprolol $100 \mathrm{mg}$, pindolol $5 \mathrm{mg}$ ) or the diuretic combination of hydrochlorothiazide/ amilorid $25 / 2.5 \mathrm{mg}$ ) given in a single daily dose. The newer drugs group was treated with an ACE-I (enalapril $10 \mathrm{mg}$ or lisinopril $10 \mathrm{mg}$ ) or a dihydropyridine calcium channel blocker (felodipine $2.5 \mathrm{mg}$ or isradipine $2-5 \mathrm{mg}$ ) daily. Importantly, blood pressure was reduced similarly in both treatment groups, so that comparison of end points between treatment arms reflects the net clinical benefit of each drug over and above blood pressure lowering efficacy. The primary end point was a composite of fatal stroke, fatal myocardial infarction and other fatal cardiovascular disease and occurred in almost exactly the same proportion (19.8 events/1000 patient years) in both treatment arms (RR 0.99, $\mathrm{p}=0.89$ ). The conclusion of this trial was that the older and newer antihypertensive drugs tested in this trial showed similar efficacy in preventing cardiovascular mortality and major events and therefore, the main importance for the prevention of such events would lie in the blood pressure lowering of these drugs rather than in the mechanism of action.

In a randomized study, ${ }^{46}$ the clinical efficacy and tolerability of irbesartan 150 to $300 \mathrm{mg}$ was compared to that of enalapril 10 to $20 \mathrm{mg}$ among elderly patients with mild to moderate hypertension. Both agents were well tolerated, the only significant difference being more frequent cough in the enalapril group. However, there was no difference in efficacy between the two agents compared.

Although not primarily studies of elderly subjects, the patients included in the Antihypertensive and Lipid Lowering Treatment to Prevent Heart Attack (ALLHAT) trial, ${ }^{47}$ the Nordic Diltiazem study (NORDIL), ${ }^{48,49}$ Valsartan Antihypertension Long-Term Use (VALUE) $)^{50}$ and Anglo-Scandinavian Cardiac Outcomes Trial-Blood Pressure Lowering Arm (ASCOT-BPLA) (ASCOT) trials ${ }^{51}$ had mean ages $>65$ years of age.

The ALLHAT patients had a mean age of 67 years. This was a randomized clinical trial comparing chlorthalidone, the dihydropyridine calcium channel blocker amlodipine and the ACE-I lisinopril as first-line therapy in hypertension. Add on of clonidine and reserpine was allowed for those who did not reach treatment target. All medications reduced prespecified end points of cardiovascular disease similarly with the exception that heart failure rates were about $40 \%$ higher in the amlodipine group than for chlorthalidone. In a prespecified subgroup of patients aged 65 years or older, combined coronary heart disease, combined cardiovascular disease and heart failure rates were significantly higher with lisinopril than with chlorthalidone. ${ }^{52}$ Combined cardiovascular disease and stroke rates were also significantly lower among patients receiving amlodipine compared with lisinopril in an elderly subpopulation of the ALLHAT study. ${ }^{53}$ There were no major differences in outcome in the elderly subgroup compared to the overall study population.

A subanalysis of the NORDIL study addressed the effect of age, sex, severity of hypertension and heart rate on outcome in a prospective, randomized, open label, blinded end point designed (PROBE) trial comparing the calcium channel blocker diltiazem with diuretic/beta-blocker based treatment. ${ }^{49}$ SBP was reduced more effectively in the diuretic/beta-blocker group, a difference of $3 \mathrm{mmHg}$ $(\mathrm{p}<0.001)$. The primary composite end point of cardiovascular death, cerebral stroke and myocardial infarction was nevertheless similar for both treatment arms. However, fatal and non-fatal stroke was reduced by $20 \%(\mathrm{p}=0.04)$ in the diltiazem group with a non-significant trend towards an increase in the rate of myocardial infarction. These results were more pronounced in the subgroup of patients with baseline SBP $>170 \mathrm{mmHg}$, DBP of $105 \mathrm{mmHg}$ or higher and pulse pressure over $65 \mathrm{mmHg}$. The favorable effect of the calcium channel blocker was present across all subgroups when analyzed according to age, sex, severity of hypertension and heart rate.

The ALLHAT and NORDIL studies therefore indicate that thiazide diuretics and calcium channel blockers might be more effective in stroke prevention than are ACE-I and betablockers. This is supported by a meta-analysis by Lindholm et $\mathrm{al}^{54}$ who found that the risk of stroke was $16 \%$ higher with beta-blockers than with other antihypertensive agents.

The VALUE trial ${ }^{50}$ set out to evaluate for the first time by head-to-head comparison whether treatment with an ARB (valsartan) would reduce cardiac-related morbidity and mortality when compared with similar blood pressure control with the dihydropyridine calcium channel blocker amlodipine. The focus of this trial was on cardiac events, and to be eligible, patients had to have either coronary artery disease or be of considerable risk thereof. Effects on stroke rate were secondary end points in this study. As it turned out the mean age of the included patients was 67.2 years and $92 \%$ had previously treated hypertension. The mean blood pressure level at study entry was $155 / 92 \mathrm{mmHg}$. At the time of the study, amlodipine was a much more frequently prescribed 
drug than was valsartan. Consequently, a larger proportion of patients randomized to the amlodipine arm continued the medication they had been taking prior to study enrolment than patients randomized to the valsartan arm, most of which were taking the ARB for the fist time after being previously treated with another antihypertensive agent. This difference between treatment groups probably lead to a very important result of the VALUE trial, that the achieved blood pressure in the amlodipine group was on average $4.3 \mathrm{mmHg}$ lower than in the valsartan group in the early months, a difference that was still $2.2 \mathrm{mmHg}$ at the end of the 5 year follow-up period. The study was therefore flawed and it is difficult to draw definitive conclusions from the main results of the trial which were that there was no difference between treatment groups in the rate of the primary end point (myocardial infarction, aborted myocardial infarction or hospitalization for congestive heart failure).

A similar problem arose in the ASCOT-BPLA. ${ }^{51}$ This was a trial aiming at answering the question whether newer antihypertensive agents (amlodipine 5-10 mg with optional addition of the ACE-I perindopril 4-8 $\mathrm{mg}$ ) were superior to conventional first-line treatment (atenolol with optional addition of the thiazide diuretic bendroflumethiazide $1.25-2.5 \mathrm{mg}$ ). This was a randomized double blind, trial that enrolled over 19,000 hypertensive patients with at least 3 other cardiovascular risk factors. There was no difference between treatment groups in the primary outcome of nonfatal myocardial infarction and fatal coronary heart disease. However, there was a significant $23 \%$ relative reduction in the rate of fatal and nonfatal stroke in the amlodipine-based group $(p=0.0003)$ and a significant reduction of both all cause $(\mathrm{p}<0.05)$ and cardiovascular mortality $(\mathrm{p}=0.001)$ when the study was stopped prematurely by the data safety monitoring board after 5.5 years of follow-up. Much the same as in the VALUE trial, there was a significant imbalance between treatment groups that was $2.7 / 1.9 \mathrm{mmHg}$ in favor of the amlodipine based regimen $(p<0.0001)$. Nevertheless, the authors conclude that the ASCOT trial supports the use of newer drugs, in multi-drug combinations, to modify risk factors and/or metabolic disturbances, especially in patients with complicated hypertension.

A more definitive conclusion can though be drawn from the results of the Losartan Intervention for Endpoint Reduction (LIFE) study. ${ }^{55}$ This was the fist trial comparing two active antihypertensive medications to show a clear effect of one treatment arm in reducing cardiovascular events. The trial included patients with hypertension and left ventricular hypertrophy comparing the ARB losartan with the beta-blocker atenolol. Hydrochlorothiazide was added to both arms to reach treatment goals. Losartan treatment resulted in a $25 \%$ relative reduction in stroke compared with atenolol. In a substudy of patients with isolated systolic hypertension ${ }^{56} 1326$ patients with SBP 160 to $200 \mathrm{mmHg}$ and DBP of less than $90 \mathrm{mmHg}$ were recruited. The mean blood pressure at randomization was $174 / 83 \mathrm{mmHg}$ and the mean age of the patients was 70 years. The primary end point was a composite of cardiovascular death, stroke or myocardial infarction. After a mean follow-up period of 4.7 years the primary end point was reduced by $25 \%$ by losartan treatment compared with atenolol $(\mathrm{p}=0.06)$. After adjustment for risk and degree of left ventricular hypertrophy the relative risk reduction was $29 \%(\mathrm{p}=0.02)$. There was a significant reduction in cardiovascular mortality $(46 \%, \mathrm{p}=0.01)$, non-fatal and fatal stroke $(40 \%, \mathrm{p}=0.02)$, new onset diabetes $(38 \%$, $\mathrm{p}=0.04)$ and total mortality $(38 \%, \mathrm{p}=0.046)$. Importantly, there was no significant difference between treatment groups in blood pressure throughout the study. The LIFE study is thus a landmark trial indicating that high risk hypertensive and predominantly elderly patients (with or without isolated systolic hypertension) have a mortality and morbidity benefit from treatment with losartan compared to atenolol.

These results have strongly influenced current international guidelines in that beta-blockers are no longer regarded as first line treatment of hypertension unless compelling indication and co-morbidities dictate otherwise. The LIFE study is also remarkable for the fact that the ARB losartan seems to reduce the risk of stroke more than does atenolol and it was the first trial to indicate that ARBs are in addition to calcium antagonists first-line drugs in stroke prevention for patients with hypertension.

The same conclusion was drawn from the Blood Pressure Lowering Trialists' Collaboration analysis ${ }^{57}$ and the JIKEI Heart Study ${ }^{58}$ that both confirmed the organ protective effects of ARBs.

The majority of patients with type 2 hypertension will need combination treatment to reach treatment targets. Current guidelines ${ }^{6,28}$ dictate the use of combinations as first-line treatment in these patients, of which one should be a thiazide diuretic. These recommendations are challenged by the recently published ACCOMPLISH trial results. ${ }^{59}$ The main objective of this study was to compare the effect of two combination therapies on clinical end points among high risk patients with hypertension. These were 11,506 patients 55 years and older with SBP $160 \mathrm{mmHg}$ or higher. All had a history of hypertension treatment and were of high risk. The combinations tested were benazepril/amlodipine 
against benazepril/hydrochlorothiazide. The data safety monitoring board stopped the trial early because of a $20 \%$ $(p<0.001)$ lower rate of major adverse cardiac events in the benazepril/amlodipine combination compared to benazepril/ hydrochlorothiazide.

Taken together, the evidence from randomized clinical trials to date confirm that effective blood pressure control and end organ protection can be achieved by any of the following classes of antihypertensive agents; thiazide diuretics, betablockers, calcium channel antagonists, ACE-I and ARBs. Until recently however, clinicians have had little data to compare the relative efficacy of these agents either as monotherapy or in various combinations. The mounting evidence now available challenges previous and current guidelines in that optimal clinical results seem to be obtainable by agents that block the RAAS system at different levels in combination with calcium channel blockers rather than with thiazide diuretics or beta-blockers. Within the RAAS cascade, combination therapy is also an attractive alternative.

\section{Renin inhibition}

In preclinical studies, the DRI aliskiren has been shown to have organ protective effects. ${ }^{60-63}$ Recent clinical end point trials indicate that aliskiren might also have end organ protective effects similar to ACE-I and ARBs in high risk patients.

Several placebo-controlled trials have assessed the antihypertensive effects of aliskiren. ${ }^{59,64-68}$ In these trials, aliskiren was found to be both effective and well tolerated. The blood pressure lowering effect in these trials was comparable or greater than those seen in other trials of hydrochlorothiazides, irbesartan and amlodipine. The results of major clinical trials of aliskiren are summarized in Table 1.

A few studies have compared the blood pressure lowering effect of aliskiren with other antihypertensive agents. ${ }^{68-74}$ Pool et a ${ }^{68}$ investigated the blood pressure lowering effect of aliskiren alone or in combination with valsartan in a randomized clinical trial including 1123 patients with mild to moderate hypertension ( $\mathrm{msDBP} \geq 95 \mathrm{mmHg}$ ). They found both aliskiren and valsartan to produce dose-related reduction in both systolic and DBP in doses ranging from 75 to $300 \mathrm{mg}$ and 80 to $320 \mathrm{mg}$ respectively. The co-administration of aliskiren and valsartan produced a greater antihypertensive effect than either agent alone and comparable to valsartan/ hydrochlorothiazide, with similar tolerability compared to the component monotherapies and to placebo.

Oparil et al conducted a randomized clinical trial ${ }^{71}$ of 1797 hypertensive patients (msDBP $95-109 \mathrm{mmHg}$ ) treated with either aliskiren $150 \mathrm{mg}$ od, valsartan $160 \mathrm{mg}$ od, a combination of the two or placebo for 4 weeks. Thereafter, forced titration was made to the double doses for another 4 weeks. The combination of aliskiren/valsartan 300/320 mg lowered the mean seated DBP from baseline by $12.2 \mathrm{mmHg}$, that was significantly more than for placebo or either monotherapy (9.0 and $9.7 \mathrm{mmHg}$ for aliskiren and valsartan respectively, $\mathrm{p}<0.0001)$. The aliskiren/valsartan combination also lowered mean seated SBP (msSBP) significantly by $17.2 \mathrm{mmHg}$ as compared to aliskiren $(13.0 \mathrm{mmHg})$ and valsartan (12.8 $\mathrm{mmHg}$ ) treatment respectively, $\mathrm{p}<0.0001)$. Rates of adverse events were similar in all groups.

Dahlöf et a ${ }^{75}$ performed a meta-analysis of 8481 patients included in placebo controlled trials with aliskiren as active treatment. The blood pressure lowering effects of aliskiren 150 and $300 \mathrm{mg}$ od were 12.5/10.1 and 15.2/11.8 $\mathrm{mmHg}$ respectively from baseline compared to $6.2 / 5.9 \mathrm{mmHg}$ for placebo $(\mathrm{p}<0.0001)$.

In a study of obese hypertensive patients (ms DBP 95-109 mmHg, body mass index $30 \mathrm{~kg} / \mathrm{m}^{2}$ or higher), not responsive to hydrochlorothiazide monotherapy, ${ }^{70}$ Jordan et al compared the effect of aliskiren, irbesartan, amlodipine or placebo as add on treatment in conventional doses. After 8 weeks of treatment the aliskiren/hydrochlorothiazide $300 / 25 \mathrm{mg}$ combination resulted in a $15.8 / 11.9 \mathrm{mmHg}$ lowering of blood pressure that was similar to those obtained by irbesartan/hydrochlorothiazide $300 / 25 \mathrm{mg}$ and amlodipine/hydrochlorothiazide $10 / 25 \mathrm{mg}$. The tolerability of aliskiren/hydrochlorothiazide was similar to that of placebo/hydrochlorothiazide.

In a dose escalating study, Stanton et $\mathrm{al}^{72}$ compared the effects of aliskiren (37.5-300 mg od) to that of losartan $100 \mathrm{mg}$ in 226 patients with mild to moderate hypertension (mean daytime ambulatory SBP $\geq 140 \mathrm{mmHg}$ ) during 4 weeks of treatment. Dose-dependent reductions were seen in systolic ambulatory blood pressure and plasma renin activity, but the blood pressure lowering effects of aliskiren (75-300 mg) were not significantly different from those of losartan $100 \mathrm{mg}$.

The antihypertensive effect and safety of aliskiren 150 to $300 \mathrm{mg}$ was compared to that of ramipril 5 to $10 \mathrm{mg}$ both as monotherapy and combination of the two in a randomized trial of 837 diabetic patients with hypertension (msDBP 96-109 mmHg). ${ }^{73}$ Aliskiren was well tolerated either as monotherapy or combination with ramipril. After 8 weeks of treatment the patients receiving combination treatment had 4.6/2.1 mmHg lower mean blood pressure than either monotherapy. 
A randomized study ${ }^{74}$ compared the efficacy and tolerability of aliskiren-based therapy with ramiprilbased therapy among 846 hypertensive patients (msDBP $95-109 \mathrm{mmHg}$ ) during 6 months of treatment. Aliskiren was given 150 to $300 \mathrm{mg}$ with ramipril 5 to $10 \mathrm{mg}$ as an active comparator. Hydrochlorothiazide 12.5 to $25 \mathrm{mg}$ was added in each arm in case of inadequate blood pressure control. Aliskiren provided significantly better blood pressure reduction (msSBP 17.9 vs $15.2 \mathrm{mmHg}, \mathrm{p}=0.0036, \mathrm{mDBP}$ $13.2 \mathrm{vs} 12.0 \mathrm{mmHg}, \mathrm{p}=0.025$ ) and resulted in higher rates of blood pressure control ( $61.4 \%$ vs $53.0 \%, p=0.0205)$.

Similar results were seen in a trial comparing aliskiren $150 \mathrm{mg}$ with atenolol $50 \mathrm{mg} .{ }^{69}$ After 12 weeks of treatment the blood pressure lowering effects of both agents were similar (14.3/11.3 vs $14.3 / 11.7 \mathrm{mmHg}$ respectively) although the combination of both was more effective than either monotherapy (17.3/14.1 mmHg).

These studies confirm that aliskiren, either alone or in several combinations, is well tolerated and has blood pressure lowering effects similar to the diverse comparators. However, these trials did not focus on end organ protection and typically included patients $50-55$ years of age.

\section{End organ protection with aliskiren}

In the AVOID trial ${ }^{76} 599$ patients with type 2 diabetes mellitus and hypertension with nephropathy, were studied in a double blind randomized trial. They were optimally treated with antihypertensive medication including losartan $100 \mathrm{mg}$ od and received in addition aliskiren vs placebo. At baseline, the mean seated blood pressure was relatively well controlled (135/78 $\mathrm{mmHg})$. The primary end point was decrease in urinary albumin to creatinin ratio (UACR) after 6 months of treatment. The primary end point was reduced by $20 \%(\mathrm{p}<0.001)$ in the aliskiren group as compared to placebo and reduction of more than $50 \%$ in UACR was seen significantly more often in the aliskiren group (24.7\%) than in the placebo group (12.5\%). This antiproteinuric effect was reached in the aliskiren-treated patients although the reductions in mean SBP $(2 \mathrm{mmHg}, \mathrm{p}=0.07)$ and DBP $(1 \mathrm{mmHg}, \mathrm{p}=0.08)$ were only marginal. It was concluded that aliskiren might have renoprotective effects that were independent of its blood pressure lowering effects in patients with diabetes and hypertension with nephropathy who are receiving recommended renoprotective treatment.

The Aliskiren Observation of Heart Failure Treatment (ALOFT) investigators studied the effects of adding aliskiren to an ACE-I in patients with heart failure. ${ }^{77}$ Patients $(n=302)$ with New York Heart Association II-IV heart failure and current or past history of hypertension were included in a randomized double blind trial. Three months treatment of aliskiren $150 \mathrm{mg}$ or placebo was added to a previous regimen of ACE-I (or ARB) and beta-blocker. The mean age of the patients was 68 years and their mean left ventricular ejection fraction was $31 \%$. The mean seated blood pressure at study entry was $129 / 77 \mathrm{mmHg}$. The systolic BP did not change significantly between treatment groups, but there was a marginal effect of msDBP lowering (2.9 vs $0.2 \mathrm{mmHg}$, $\mathrm{p}=0.06$ ) for aliskiren vs placebo respectively. The mean N-terminal pro-BNP level was approximately $2100 \mathrm{pg} / \mathrm{mL}$ at baseline. The plasma N-terminal pro-BNP rose by $762( \pm 6123)$ $\mathrm{pg} / \mathrm{mL}$ in the placebo group and fell by $244( \pm 2015) \mathrm{pg} / \mathrm{mL}$ in the aliskiren group after 12 weeks of treatment. Total BNP and urinary aldosterone were also reduced by aliskiren. It was concluded that addition of aliskiren to an ACE-I (or ARB) and beta-blocker had favorable neurohormonal effects in heart failure and appeared to be well tolerated.

The ALLAY study focused on the effects of aliskiren alone or in combination with losartan compared to losartan alone in the reduction of left ventricular hypertrophy among 460 overweight hypertensive patients with left ventricular hypertrophy. ${ }^{78}$ This study showed that aliskiren reduced left ventricular hypertrophy as effectively as losartan $(-5.4 \%$ vs $-4.7 \%, \mathrm{p}=\mathrm{ns})$. However no effect on the primary end point was reached in this study as the combination of the two agents was not significantly more effective than each monotherapy alone in reducing left ventricular hypertrophy. The decrease in left ventricular hypertrophy turned out to be directly related to the level of blood pressure reduction achieved. However, at baseline the blood pressure was approximately $145 / 89 \mathrm{mmHg}$ and was similarly reduced in all treatment groups (aliskiren group by $6.5 / 3.8 \mathrm{mmHg}$, losartan group by $5.5 / 3.7 \mathrm{mmHg}$ and aliskiren/valsartan combination group by $6.6 / 4.6 \mathrm{mmHg}$, $\mathrm{p}=\mathrm{ns})$. The lack of difference between treatment arms might be due to the fact that additional treatment was allowed to reach treatment targets in all groups.

\section{Aliskiren and the elderly}

The safety and tolerability of aliskiren was studied in 355 elderly patients ( 65 years or older) with systolic hypertension (msSBP $145-179 \mathrm{mmHg}$ or mean ambulatory SBP $135 \mathrm{mmHg}$ or higher). ${ }^{79}$ After 8 weeks of treatment aliskiren doses of 75, 150 and $300 \mathrm{mg}$ and lisinopril $10 \mathrm{mg}$ lowered mean ambulatory SBP by 8.4, 7.1, 8.7 and $10.2 \mathrm{mmHg}$ respectively. Mean ambulatory DBP was lowered by 4.5 ; 3.6; 3.9 and $6.3 \mathrm{mmHg}$ respectively. All treatment groups lowered $\mathrm{msSBP}$ and $\mathrm{msDBP}$ significantly compared to 
Table I Major clinical trials of aliskiren

\begin{tabular}{|c|c|c|c|c|}
\hline Reference & $\begin{array}{l}\text { Publication } \\
\text { year }\end{array}$ & $\begin{array}{l}\text { Number } \\
\text { of patients }\end{array}$ & Treatment & Main results \\
\hline Gradman et $\mathrm{a}^{164}$ & 2005 & 652 & $\begin{array}{l}\text { Aliskiren 150-600 } \\
\text { Irbesartan } 150 \\
\text { Placebo }\end{array}$ & $\begin{array}{l}\text { Dose ranging study, all aliskiren doses } \\
\text { showing significant effect on SBP and DBP } \\
\text { compared to placebo. Plateau at } 300 \mathrm{mg} \\
\text { aliskiren with similar effect of aliskiren } \\
150 \mathrm{mg} \text { and irbesartan } 150 \mathrm{mg}\end{array}$ \\
\hline Villamil et a ${ }^{65}$ & 2007 & 2776 & $\begin{array}{l}\text { Aliskiren 75-300 } \\
\text { HCTZ 6.25-25 } \\
\text { Aliskiren/HCTZ 75-300/6.25-25 }\end{array}$ & $\begin{array}{l}\text { Dose ranging study, all aliskiren doses } \\
\text { showing significant dose-dependent effect } \\
\text { on DBP compared to placebo. Aliskiren } \\
\text { I50-300 mg, all HCTZ doses and all } \\
\text { combinations superior to placebo in SBP } \\
\text { effect.Aliskiren lowered PRA }\end{array}$ \\
\hline
\end{tabular}

\begin{tabular}{|c|c|c|}
\hline Oh et $a^{166}$ & & 672 \\
\hline
\end{tabular}

Placebo

Dose ranging study, all aliskiren doses showing significant dose-dependent effect on SBP and DBP compared to placebo. Aliskiren resulted in PRA reductions and increased PRC

\begin{tabular}{|c|c|c|c|}
\hline Kushiro et al ${ }^{67}$ & 2006 & 455 & $\begin{array}{l}\text { Aliskiren } 75-300 \\
\text { Placebo }\end{array}$ \\
\hline Pool et al ${ }^{68}$ & 2007 & 1123 & $\begin{array}{l}\text { Aliskiren 75-300 } \\
\text { Valsartan 80-320 } \\
\text { Aliskiren/valsartan 75-300/80-320 } \\
\text { Valsartan/HCTZ I60/I2.5 } \\
\text { Placebo }\end{array}$ \\
\hline Dietz $^{69}$ & 2008 & 694 & $\begin{array}{l}\text { Aliskiren } 150 \\
\text { Atenolol } 50\end{array}$ \\
\hline Jordan et $\mathrm{al}^{70}$ & 2007 & 490 & $\begin{array}{l}\text { Aliskiren I50-aliskiren/HCTZ 300/25 } \\
\text { Irbesartan I50-irbesartan/HCTZ } \\
300 / 25 \\
\text { Amlodipine 5-amlodipine/HCTZ } \\
\text { I0/25 } \\
\text { Placebo/HCTZ } 25\end{array}$ \\
\hline Oparil S et al $\left.\right|^{71}$ & 2007 & 1797 & $\begin{array}{l}\text { Aliskiren } 150-300 \\
\text { Valsartan } 160-320 \\
\text { Aliskiren/valsartan I50/I60-300/320 } \\
\text { Placebo }\end{array}$ \\
\hline Stanton et $\mathrm{al}^{72}$ & 2003 & 226 & $\begin{array}{l}\text { Aliskiren } 37.5-300 \\
\text { Losartan } 100\end{array}$ \\
\hline Uresin et $\mathrm{al}^{73}$ & 2007 & 837 & $\begin{array}{l}\text { Aliskiren } 150-300 \\
\text { Ramipril 5-10 } \\
\text { Aliskiren/ramipril 5/150-10/300 }\end{array}$ \\
\hline Andersen et $\mathrm{a}^{74}$ & 2008 & 842 & $\begin{array}{l}\text { Aliskiren I50-300 (HCTZ I2.5-25) } \\
\text { Ramipril 5-10 (HCTZ I2.5-25) }\end{array}$ \\
\hline Dahlöf $f^{75}$ & 2007 & 8481 & $\begin{array}{l}\text { Aliskiren } 150-300 \\
\text { Placebo (meta-analysis) }\end{array}$ \\
\hline
\end{tabular}

Aliskiren produced a significant and dose-dependent reduction in SBP and DBP compared to placebo. Placebo-like tolerability of aliskiren

Aliskiren and valsartan both produced dose-related reductions in SBP and DBP. Co-administration more effective than either monotherapy and comparative to valsartan/HCTZ. Well tolerated

Similar blood pressure reduction with aliskiren and atenolol. Combination was more effective than either monotherapy

BP lowering similar for aliskiren/HCTZ as for irbesartan/HCTZ and amlodipine/ HCTZ. Aliskiren/HCTZ tolerated similar to placebo/HCTZ

Combination of aliskiren and valsartan more effective in reducing both SBP and $\mathrm{DBP}$ than either monotherapy alone

Similar dose-dependent reduction in ABPM for aliskiren and losartan

Patients with diabetes. Aliskiren well tolerated either alone or in combination with ramipril. Combination treatment reduced BP 4.6/2.I over monotherapy

Aliskiren provided significantly better SBP and $D B P$ reduction and higher rates of $B P$ control than ramipril-based therapy

Aliskiren 150 and $300 \mathrm{mg}$ treatment resulted in a significant $12.5 / 10.1$ and 15.2/1 $1.8 \mathrm{mmHg}$ lowering in BP compared to $6.2 / 5.9 \mathrm{mmHg}$ for placebo

(Continued) 
Table I (Continued)

\begin{tabular}{|c|c|c|c|c|}
\hline Reference & $\begin{array}{l}\text { Publication } \\
\text { year }\end{array}$ & $\begin{array}{l}\text { Number } \\
\text { of patients }\end{array}$ & Treatment & Main results \\
\hline $\begin{array}{l}\text { Parving } \mathrm{H}-\mathrm{H} \text { et } \mathrm{al}^{76} \\
\text { AVOID trial }\end{array}$ & 2008 & 599 & $\begin{array}{l}\text { Aliskiren } 150-300 \\
\text { Placebo }\end{array}$ & $\begin{array}{l}\text { Pts with diabetes and nephropathy } \\
\text { optimally treated with losartan at baseline. } \\
\text { UACR reduced } 20 \% \text { by aliskiren treatment } \\
\text { compared to placebo without significant } \\
\text { reductions in BP. UACR reduction of } \\
50 \% \text { or more was seen twice as often in } \\
\text { aliskiren group }\end{array}$ \\
\hline $\begin{array}{l}\text { McMurray et al }{ }^{77} \\
\text { ALOFT }\end{array}$ & 2008 & 302 & $\begin{array}{l}\text { Aliskiren } 150 \\
\text { Placebo }\end{array}$ & $\begin{array}{l}\text { Pts with CHF and HT on baseline } \\
\text { treatment with ACE-I (or ARB) and } \\
\text { beta-blocker. Aliskiren was well tolerated } \\
\text { and showed favorable neurohormonal } \\
\text { effects (pro-BNP lowering) }\end{array}$ \\
\hline $\begin{array}{l}\text { Solomon et } \mathrm{al}^{78} \\
\text { ALLAY }\end{array}$ & 2008 & 460 & $\begin{array}{l}\text { Aliskiren } \\
\text { Losartan } \\
\text { Aliskiren/losartan }\end{array}$ & $\begin{array}{l}\text { Aliskiren and losartan equally effective in } \\
\text { reducing left ventricular hypertrophy, with } \\
\text { no additional effect from combination } \\
\text { therapy }\end{array}$ \\
\hline Verdecchia et a ${ }^{79}$ & 2007 & 355 & $\begin{array}{l}\text { Aliskiren } 75-300 \\
\text { Lisinopril I0 }\end{array}$ & $\begin{array}{l}\text { Elderly population ( } 65 \text { years and older) } \\
\text { with HT. Aliskiren was well tolerated. All } \\
\text { treatment groups lowered mean seated } \\
\text { SBP and DBP compared to baseline }\end{array}$ \\
\hline Schmieder et a ${ }^{80}$ & 2008 & 1124 & $\begin{array}{l}\text { Aliskiren } 300 \text { (amlodipine 5-10) } \\
\text { HCTZ } 25 \text { (amlodipine 5-10) }\end{array}$ & $\begin{array}{l}\text { Post-hoc analysis comparing elderly and } \\
\text { very elderly to younger pts with HT.After } \\
52 \text { weeks aliskiren provided significantly } \\
\text { greater reductions in SBP and PP among } \\
\text { elderly and very elderly as compared to } \\
\text { younger pts. Aliskiren was well tolerated } \\
\text { and more effective than HCTZ }\end{array}$ \\
\hline Yarows et al ${ }^{81-82}$ & 2008 & 1797 & $\begin{array}{l}\text { Aliskiren } \\
\text { Valsartan } \\
\text { Aliskiren/valsartan }\end{array}$ & $\begin{array}{l}\text { Subgroup analysis comparing elderly with } \\
\text { younger patients. Aliskiren monotherapy } \\
\text { and aliskiren/valsartan combinations were } \\
\text { equally well tolerated in elderly as in } \\
\text { younger pts. Combination treatment more } \\
\text { effective than monotherapy in SBP lower- } \\
\text { ing and control rates among elderly pts }\end{array}$ \\
\hline Gradman et al ${ }^{83}$ & 2008 & 776 & $\begin{array}{l}\text { Aliskiren } 150 \\
\text { Aliskiren } 300 \\
\text { Placebo }\end{array}$ & $\begin{array}{l}\text { Pooled analysis of } 8 \text { RCTs comparing effi- } \\
\text { cacy of aliskiren among elderly vs younger } \\
\text { pts with HT. Aliskiren I } 50 \text { and } 300 \mathrm{mg} \\
\text { lowered BP significantly compared with } \\
\text { placebo independent of age in pts with } \\
\text { hypertension }\end{array}$ \\
\hline $\begin{array}{l}\text { Duprez et al }{ }^{84} \\
\text { AGELESS }\end{array}$ & 2008 & 900 & $\begin{array}{l}\text { Aliskiren I50-300 (HCTZ I2.5-25) } \\
\text { (amlodipine 5-10) } \\
\text { Ramipril 5-10 (HCTZ I2.5-25) } \\
\text { (amlodipine 5-10) }\end{array}$ & $\begin{array}{l}\text { Dose escalating study of aliskiren-HCTZ- } \\
\text { amlodipine vs ramipril-HCTZ-amlodipine } \\
\text { among elderly pts with HT. Aliskiren-based } \\
\text { therapy was superior to ramipril-based } \\
\text { therapy at } 12 \text { weeks and non-inferior } \\
\text { at } 36 \text { weeks in msSBP lowering. A higher } \\
\text { control rate and less need for add-on } \\
\text { therapy was seen for aliskiren compared } \\
\text { with ramipril therapy }\end{array}$ \\
\hline
\end{tabular}

Abbreviations: ABPM, ambulatory blood pressure monitoring; ACE-I, angiotensin converting enzyme inhibitor; ARB, angiotensin receptor blocker; BNP, brain natriuretic peptide; BP, blood pressure; CHF, congestive heart failure; HCTZ, hydrochlorothiazide; HT, hypertension; DBP, diastolic blood pressure; SBP, systolic blood pressure; msSBP, mean seated systolic blood pressure; PRA, plasma renin activity; PRC, plasma renin concentration; PP, pulse pressure; RCTs, randomized clinical trials; UACR, urinary albumin to creatinine ratio. 
baseline and the proportion of patients that reached blood pressure control $(<140 / 90 \mathrm{mmHg})$ with aliskiren $300 \mathrm{mg}$ was greater than with aliskiren $75 \mathrm{mg}(36.2 \%$ vs $24.2 \%$, $\mathrm{p}=0.033$ ). Importantly, there was no evidence of doserelated increases in the incidence of adverse events in this elderly population.

In a post-hoc analysis of a double blind randomized trial, Schmieder et $\mathrm{al}^{80}$ studied the blood pressure lowering effect of aliskiren $300 \mathrm{mg}$ vs hydrochlorothiazide $25 \mathrm{mg}$ in 1124 elderly ( $\geq 65$ years) and very elderly ( $\geq 75$ years) patients with hypertension. Amlodipine 5 to $10 \mathrm{mg}$ was added as needed to reach target blood pressure of 140/90. After 52 weeks aliskiren based treatment provided significantly greater reductions in SBP and pulse pressure among the elderly and very elderly patients than in younger patients $(\mathrm{p}<0.05)$. Blood pressure control rates were greater with aliskiren-based therapy than with hydrochlorothiazide therapy in the elderly and aliskiren was well tolerated. This study indicates that aliskiren is well tolerated in elderly and very elderly patients and is more effective than thiazide diuretics in lowering systolic hypertension and elevated pulse pressure.

In another subgroup analysis ${ }^{81,82}$ of a randomized double blind trial including 1797 patients with hypertension, Yarrows et al studied the effect of aliskiren, valsartan and the combination of both in elderly patients compared to those younger than 65 years of age. Aliskiren monotherapy and aliskiren/valsartan combinations were equally well tolerated in the elderly as in younger patients. The combination provided greater reductions in SBP and blood pressure control rates than did valsartan monotherapy in the elderly patients. The effect of aliskiren/valsartan and high dose valsartan on pulse pressure was greater in elderly patients than in younger patients.

In a pooled analysis of 8 randomized clinical trials of hypertensive patients (msDBP 95-109 $\mathrm{mmHg}$ ) treated with aliskiren Gradman et $\mathrm{al}^{83}$ found aliskiren to provide effective blood pressure reductions and improve responder rates compared with placebo, and independent of age.

Finally, the AGELESS study, ${ }^{84}$ presented at the American Heart Association 2008 Scientific Sessions, was a randomized trial of hypertensive patients, 65 years of age and older. Nine hundred and one patients received either aliskiren $150 \mathrm{mg}$ od or ramipril $5 \mathrm{mg}$ od for 4 weeks. If the treatment goal of $140 \mathrm{mmHg}$ SBP was not reached at 4 weeks, the doses were doubled. At 12 weeks, hydrochlorothiazide 12.5 to $25 \mathrm{mg}$ could be added, followed by amlodipine 5 to $10 \mathrm{mg}$ daily. The mean age of the study population was 72 years and $53 \%$ were females. Patients 75 years or older made up $32.5 \%$ of the population. The incidence of adverse events was similar between groups. At 12 weeks end point aliskiren treatment resulted in a significantly greater reduction of SBP than ramipril (13.6 vs $11.3 \mathrm{mmHg}, \mathrm{p}<0.0001$ ) (mean difference $-2.32 \mathrm{mmHg}, 95 \% \mathrm{CI}-4.34$ to $0.30, \mathrm{p}=0.0421$ ). At the 36-week end point, aliskiren-based treatment was noninferior to ramipril based treatment although the difference $(-1.92,95 \% \mathrm{CI}-4.03$ to $0.19, \mathrm{p}=0.0747)$ did not reach statistical significance.

In summary, renin inhibition with aliskiren has been shown to be at least equally effective for blood pressure lowering as ramipril, losartan, valsartan, lisinopril, atenolol and hydrochlorothiazide both as monotherapy and in combinations. Aliskiren has shown some organ protective effects and is well tolerated and effective in both elderly hypertensive as well as hypertensive patients in general.

\section{Conclusion}

High blood pressure is a major risk factor for cardiovascular and renal complications. This risk is especially well established in the elderly population. Contrary to earlier belief, a number of clinical trials have shown blood pressure treatment to be both safe and effective in end organ protection in elderly patients. Most of the elderly will need combination therapy to control their blood pressure and achieve optimal end organ protection. Recent trials indicate that agents blocking the RAAS might be more effective for this purpose through diverse pleiotropic effects. Calcium channel blockers, being both well tolerated, safe and effective for blood pressure control, remain first-line drugs in the treatment of hypertension in elderly patients, especially in combinations with inhibitors of the RAAS. Thiazide diuretics still have their place as first-line agents in blood pressure control as they are both inexpensive, effective and well tolerated. The DRI aliskiren has been shown to have at least comparable blood pressure lowering effects as other RAAS inhibitors, and a few early clinical trials indicate that it may provide a significant benefit in combination with other agents for end organ protective effects. Aliskiren has some theoretical advantages that could contribute to its end organ protection. However, upcoming randomized clinical trials will have to determine whether these effects translate into a significant clinical benefit to reduce end organ damage in the elderly population.

\section{Disclosures}

The author disclosures no conflicts of interest. 


\section{References}

1. Walker W, Neaton J, Cutler J, RN, Cohen J. Renal function change in hypertensive members of the Multiple Risk Factor Intervention Trial. Racial and treatment effects. The MRFIT Research Group. JAMA. 1992;268(21):3085-3091.

2. MacMahon S, Peto R, Collins R, et al. Blood pressure, stroke, and coronary heart disease : Part 1, prolonged differences in blood pressure: prospective observational studies corrected for the regression dilution bias. Lancet. 1990;335(8692):765-774.

3. Kannel WB. Blood pressure as a cardiovascular risk factor: prevention and treatment. JAMA. 1996;275:1571-1576.

4. Kearney P, Whelton M, Reynolds K, Muntner P, Whelton P, He J. Global burden of hypertension: analysis of worldwide data. Lancet. 2005;365(9455):217-223.

5. Ong KL, Cheung BMY, Man YB, Lau CP, Lam KSL. Prevalence, awareness, treatment, and control of hypertension among united states adults 1999-2004. Hypertension. 2007;49(1):69-75.

6. Chobanian AV, Bakris GL, Black HR, et al. Seventh Report of the Joint National Committee on Prevention, Detection, Evaluation, and Treatment of High Blood Pressure. Hypertension. 2003;42(6):1206-1252.

7. Fagard R. Epidemiology of hypertension in the elderly. Am J Geriatr Cardiol. 2002;11(1):23-28.

8. Dyer A, Stamler J, Shekelle R, Schoenberger J, Farinaro E. Hypertension in the elderly. Med Clin North Am. 1977;61(3):513-529.

9. Skoog I, Lernfelt B, Landahl S, et al. 15-year longitudinal study of blood pressure and dementia. Lancet. 1996;347(9009):1141-1145.

10. Lewington S, Clarke R, Qizilbash N, Peto R, Collins R, Collaboration. PS. Age-specific relevance of usual blood pressure to vascular mortality: a meta-analysis of individual data for one million adults in 61 prospective studies. Lancet. 2002;360(9349):1903-1913.

11. Franklin SS, Larson MG, Khan SA, et al. Does the relation of blood pressure to coronary heart disease risk change with aging? The Framingham Heart Study. Circulation. 2001;103(9):1245-1249.

12. Benetos A, Zureik M, Morcet J, et al. A decrease in diastolic blood pressure combined with an increase in systolic blood pressure is associated with a higher cardiovascular mortality in men. J Am Coll Cardiol. 2000;35(3):673-680.

13. Meaume S, Benetos A, Henry OF, Rudnichi A, Safar ME. Aortic pulse wave velocity predicts cardiovascular mortality in subjects $>70$ years of age. Arterioscler Thromb Vasc Biol. 2001;21(12):2046-2050.

14. Sutton-Tyrrell K, Najjar SS, Boudreau RM, et al. Elevated aortic pulse wave velocity, a marker of arterial stiffness, predicts cardiovascular events in well-functioning older adults. Circulation. 2005;111(25):3384-3390.

15. US Census Bureau. Persons 65 Years Old and Over-Characteristics by Sex:1980 to 2000.: Washington DC: Statistics Bureau 2001.

16. Franklin SS, Jacobs MJ, Wong ND, L'Italien GJ, Lapuerta P. Predominance of Isolated Systolic Hypertension Among Middle-Aged and Elderly US Hypertensives: Analysis Based on National Health and Nutrition Examination Survey (NHANES) III. Hypertension. 2001;37(3):869-874.

17. Kostis J, Davis B, Cutler J, et al. Prevention of heart failure by antihypertensive drug treatment in older persons with isolated systolic hypertension. SHEP Cooperative Research Group. JAMA. 1997;278:212-216.

18. SHEP Cooperative Research Group. Prevention of stroke by antihypertensive drug treatment in older persons with isolated systolic hypertension. Final results of the Systolic Hypertension in the Elderly Program (SHEP). JAMA. 1991;265:3255-3264.

19. Staessen JA, Thijs L, Fagard R, et al. Predicting cardiovascular risk using conventional vs ambulatory blood pressure in older patients with systolic hypertension. JAMA. 1999;282(6):539-546.

20. Danser A, Batenburg W, van Esch J. Prorenin and the (pro)renin receptor-an update. Nephrol Dial Transplant. 2007;22(5):1288-1292.

21. Gradman AH, Kad R. Renin inhibition in hypertension. J Am Coll Cardiol. 2008;51:519-528.
22. Nguyen G. The (pro)renin receptor: pathophysiological roles in cardiovascular and renal pathology. Curr Opin Nephrol Hypertens. 2007;16:129-133.

23. Gueyffier F, Bulpitt C, Boissel J-P, et al. Antihypertensive drugs in very old people: a subgroup meta-analysis of randomised controlled trials. Lancet. 1999;353(9155):793-796.

24. Beckett NS, Peters R, Fletcher AE, et al. Treatment of hypertension in patients 80 years of age or older. $N$ Engl J Med. 2008;358(18): 1887-1898.

25. European Stroke Initiative Executive Committee; EUSI Writing Committee OT, Langhorne P, Diener HC, Hennerici M, et al. European Stroke Initiative Recommendations for Stroke Management-update 2003. Cerebrovasc Dis. 2003;16(4):311-337.

26. International Society of Hypertension Writing Group. International Society of Hypertension (ISH): Statement on blood pressure lowering and stroke prevention. J Hypertens. 2003;21:651-653.

27. Alberts M. Update on the treatment and prevention of ischaemic stroke. Curr Med Res Opin. 2003;19(5):438-441.

28. Authors/Task Force M, Mancia G, De Backer G, et al. Guidelines for the management of arterial hypertension: The Task Force for the Management of Arterial Hypertension of the European Society of Hypertension (ESH) and of the European Society of Cardiology (ESC). Eur Heart J. 2007;28(12):1462-1536.

29. Dahlöf B, Hansson L, Lindholm LH, Scherstén B, Ekbom T, Wester PO. Morbidity and mortality in the Swedish Trial in Old Patients with Hypertension (STOP-Hypertension). Lancet. 1991;338(8778):1281-1285.

30. Gueyffier F, Boutitie F, Boissel JP, et al. Effect of antihypertensive drug treatment on cardiovascular outcomes in women and men: a meta-analysis of individual patient data from randomized, controlled trials. Ann Intern Med. 1997;126(10):761-767.

31. Staessen JA, Fagard R, Thijs L, et al. Randomised double-blind comparison of placebo and active treatment for older patients with isolated systolic hypertension. Lancet. 1997;350(9080):757-764.

32. Liu L, Wang J, Gong L, Liu G, Staessen J, for the Systolic Hypertension in China (Syst-China) Collaborative Group. Comparison of active treatment and placebo in older Chinese patients with isolated systolic hypertension. J Hypertens. 1998;16:1823-1829.

33. Wood D, on behalf of the EUROASPIRE III Investigators. Risk factor management in coronary patients-results from a Eurpoean wide survey. Euroaspire III. European Society of Cardiology, 2008; Munich, Germany.

34. Appel LJ, Espeland MA, Easter L, Wilson AC, Folmar S, Lacy CR. Effects of reduced sodium intake on hypertension control in older individuals: results from the Trial of Nonpharmacologic Interventions in the Elderly (TONE). Arch Intern Med. March 12, 2001 2001;161(5):685-693.

35. Thijs L, Fagard R, Lijnen P, Staessen J, Van Hoof R, Amery A. A meta-analysis of outcome trials in elderly hypertensives. J Hypertens. 1992;10:1103-1109.

36. Ekbom T, Lindholm L, Odén A, et al. A 5-year prospective, observational study of the withdrawal of antihypertensive treatment in elderly people. J Intern Med. 1994;235(6):581-588.

37. Lund-Johansen P. Stopping antihypertensive drug therapy in elderly people - a dangerous experiment? J Intern Med. 1994;235(6): 577-579.

38. Lever A, Ramsay L. Treatment of hypertension in the elderly. J Hypertens. 1995;13(6):571-579.

39. Lindholm LH, Johannesson M. Cost-benefit aspects of treatment of hypertension in the elderly. Blood Pressure. 1995;45 suppl 3:11-14.

40. Dahlöf B. Preventing stroke in hypertensive patients at risk. J Am Soc Hypertens. 2008;2(4):S38-S45.

41. Staessen J. Mortality and treated blood pressure in patients of the European Working Party on High Blood Pressure in the Elderly. Am J Med. 1991;90(3A):60S-61S.

42. Psaty B, Smith N, Siscovick D, et al. Health outcomes associated with antihypertensive therapies used as first-line agents. A systematic review and meta-analysis. JAMA. 1997;277(9):739-745. 
43. Lithell H, Hansson L, Skoog I, et al. The Study on Cognition and Prognosis in the Elderly (SCOPE): principal results of a randomized double-blind intervention trial. J Hypertens. 2003;21(5):875-886.

44. Chalmers J, Castaigne A, Morgan T, Chastang C. Long-term efficacy of a new, fixed, very-low-dose angiotensin-converting enzyme-inhibitor/ diuretic combination as fist-line therapy in elderly hypertensive patients. J Hypertens. 2000;18(3):327-337.

45. Hansson L, Lindholm LH, Ekbom T, et al. Randomised trial of old and new antihypertensive drugs in elderly patients: cardiovascular mortality and morbidity the Swedish Trial in Old Patients with Hypertension-2 study. Lancet. 1999;354(9192):1751-1756.

46. Lacourcière Y. A multicenter, randomized, double-blind study of the antihypertensive efficacy and tolerability of irbesartan in patients aged $\geq 65$ years with mild to moderate hypertension. Clin Ther. 2000;22(10):1213-1224.

47. The Allhat Officers and Coordinators for the Allhat Collaborative Research Group. Major outcomes in high-risk hypertensive patients randomized to angiotensin-converting enzyme inhibitor or calcium channel blocker vs diuretic: The Antihypertensive and LipidLowering Treatment to Prevent Heart Attack Trial (ALLHAT). JAMA. 2002;288(23):2981-2997.

48. Hansson L, Hedner T, Lund-Johansen P, et al. Randomised trial of effects of calcium antagonists compared with diuretics and [beta]-blockers on cardiovascular morbidity and mortality in hypertension: the Nordic Diltiazem (NORDIL) study. Lancet. 2000;356(9227):359-365.

49. Kjeldsen S, Hedner T, Syvertsen J, et al. Influence of age, sex and blood pressure on the principal endpoints of the Nordic Diltiazem (NORDIL) Study. J Hypertens. 2002;20(6):1231-1237.

50. Julius S, Kjeldsen SE, Weber M, et al. Outcomes in hypertensive patients at high cardiovascular risk treated with regimens based on valsartan or amlodipinee: the VALUE randomised trial. Lancet. 2004;363(9426):2022-2031.

51. Dahlöf B, Sever PS, Poulter NR, et al. Prevention of cardiovascular events with an antihypertensive regimen of amlodipinee adding perindopril as required versus atenolol adding bendroflumethiazide as required, in the Anglo-Scandinavian Cardiac Outcomes Trial-Blood Pressure Lowering Arm (ASCOT-BPLA): a multicentre randomised controlled trial. Lancet. 366(9489):895-906.

52. Moser M. Treatment of hypertension in the very elderly: a clinician's point of view. J Clin Hypertens (Greenwich). 2003;5(5):310-312.

53. Leenen FHH, Nwachuku CE, Black HR, et al. Clinical events in high-risk hypertensive patients randomly assigned to calcium channel blocker versus angiotensin-converting enzyme inhibitor in the Antihypertensive and Lipid-Lowering Treatment to Prevent Heart Attack Trial. Hypertension. 2006;48(3):374-384.

54. Lindholm LH, Carlberg B, Samuelsson O. Should [beta] blockers remain first choice in the treatment of primary hypertension? A meta-analysis. Lancet. 366(9496):1545-1553.

55. Dahlöf B, Devereux RB, Kjeldsen SE, et al. Cardiovascular morbidity and mortality in the Losartan Intervention For Endpoint reduction in hypertension study (LIFE): a randomised trial against atenolol. Lancet. 2002;359(9311):995-1003.

56. Kjeldsen SE, Dahlof B, Devereux RB, et al. Effects of losartan on cardiovascular morbidity and mortality in patients with isolated systolic hypertension and left ventricular hypertrophy: A Losartan Intervention For Endpoint Reduction (LIFE) Substudy. JAMA. 2002;288(12):1491-1498.

57. Turnbull F, Blood Pressure Lowering Treatment Trialists' Collaboration. Effects of different blood-pressure-lowering regimens on major cardiovascular events: results of prospectively-designed overviews of randomised trials. Lancet. 2003;362(9395):1527-1535.

58. Mochizuki S, Dahlöf B, Shimizu M, et al. Valsartan in a Japanese population with hypertension and other cardiovascular disease (Jikei Heart Study): a randomised, open-label, blinded endpoint morbiditymortality study. Lancet. 369(9571):1431-1439.

59. Jamerson K, Weber MA, Bakris GL, et al. Benazepril plus Amlodipinee or hydrochlorothiazide for hypertension in high-risk patients. $N$ Engl $J$ Med. 2008;359(23):2417-2428.
60. Pilz B, Shagdarsuren E, Wellner M, et al. Aliskiren, a human renin inhibitor, ameliorates cardiac and renal damage in double-transgenic rats. Hypertension. 2005;46(3):569-576.

61. Shagdarsuren E, Wellner M, Braesen J-H, et al. Complement activation in angiotensin ii-induced organ damage. Circ Res. 2005;97(7):716-724.

62. Whaley-Connell A, Habibi J, Cooper SA, et al. Effect of renin inhibition and AT1R blockade on myocardial remodeling in the transgenic Ren2 rat. Am J Physiol Endocrinol Metab. 2008;295(1):E103-109.

63. Feldman DL, Jin L, Xuan H, et al. Effects of aliskiren on blood pressure, albuminuria, and (pro)renin receptor expression in diabetic TG(mRen-2)27 rats. Hypertension. 2008;52(1):130-136.

64. Gradman AH, Schmieder RE, Lins RL, Nussberger J, Chiang Y, Bedigian MP. Aliskiren, a novel orally effective renin inhibitor, provides ose-dependent antihypertensive efficacy and placebo-like tolerability in hypertensive patients. Circulation. 2005;111(8):1012-1018.

65. Villamil A, Chrysant SGB, Calhoun DC, et al. Renin inhibition with aliskiren provides additive antihypertensive efficacy when used in combination with hydrochlorothiazide. J Hypertens. 2007;25(1):217-226.

66. Oh B-H, Mitchell J, Herron JR, Chung J, Khan M, Keefe DL. Aliskiren, an oral renin inhibitor, provides dose-dependent efficacy and sustained 24-hour blood pressure control in patients with hypertension. $J$ Am Coll Cardiol. 2007:49(11):1157-1163.

67. Kushiro T, Itakura H, Abo Y, Gotou H, Terao S, Keefe DL. Aliskiren, a novel oral renin inhibitor, provides dose-dependent efficacy and placebo-like tolerability in Japanese patients with hypertension. Hypertens Res. 2006;29(12):997-1005.

68. Pool J, Schmieder RE, Azizi M, et al. Aliskiren, an orally effective renin inhibitor, provides antihypertensive efficacy alone and in combination with valsartan. Am J Hypertens. 2007;20(1):11-20.

69. Dietz R, Dechend R, Yu C-M, et al. Effects of the direct renin inhibitor aliskiren and atenolol alone or in combination in patients with hypertension1. J Renin-Angiotensin-Aldosterone Syst. 2008;9(3):163-175.

70. Jordan J, Engeli S, Boye SW, Le Breton S, Keefe DL. Direct renin inhibition with aliskiren in obese patients with arterial hypertension. Hypertension. 2007;49(5):1047-1055.

71. Oparil S, Yarows SA, Patel S, Fang H, Zhang J, Satlin A. Efficacy and safety of combined use of aliskiren and valsartan in patients with hypertension: a randomised, double-blind trial. Lancet. 2007;370(9583):221-229.

72. Stanton A, Jensen C, Nussberger J, O'Brien E. Blood pressure lowering in essential hypertension with an oral renin inhibitor, aliskiren. Hypertension. 2003;42(6):1137-1143.

73. Uresin Y, Taylor AA, Kilo C, et al. Efficacy and safety of the direct renin inhibitor aliskiren and ramipril alone or in combination in patients with diabetes and hypertension. Journal of Renin-Angiotensin-Aldosterone System. 2007;8(4):190-200.

74. Andersen K, Weinberger MH, Egan B, et al. Comparative efficacy and safety of aliskiren, an oral direct renin inhibitor, and ramipril in hypertension: a 6-month, randomized, double-blind trial. J Hypertens. 2008;26(3):589-599.

75. Dahlöf B, Anderson D, Arora V, et al. Aliskiren, a direct renin inhibitor, provides antihypertensive efficacy and excellent tolerability independent of age or gender in patients with hypertension. J Clin Hypertens (Greenwich). 2007;9 suppl A:93.

76. Parving H-H, Persson F, Lewis JB, Lewis EJ, Hollenberg NK, the ASI. Aliskiren Combined with Losartan in Type 2 Diabetes and Nephropathy. N Engl J Med. 2008;358(23):2433-2446.

77. McMurray J, Pitt B, Latini R, et al. Effects of the oral direct renin inhibitor aliskiren in patients with symptomatic heart failure. Circ Heart Fail. 2008;1:17-24.

78. Solomon S, Appelbaum E, Manning W, et al. Effect of the direct renin inhibitor aliskiren, either alone or in combination with losartan, compared to losartan, on left ventricular mass in patients with hypertension and left ventricular hypertrophy: The Aliskiren Left Ventricular Assessment of Hypertrophy (ALLAY) Trial. Late breakeing clinical trials. American College of Cardiology 57th Scientific Sessions 2008, 2008; Chicago, USA. 
79. Verdecchia P, Calvo C, Möckel V, Keeling L, Satlin A. Safety and efficacy of the oral direct renin inhibitor aliskiren in elderly patients with hypertension. Blood Pressure. 2007;16(6):381-391.

80. Schmieder RE, Philippe T, Guerediaga J, Gorostide M, Arora V, Keefe D. Long-Term aliskiren-based therapy effectively lowers systolic blood pressure and pulse pressure in elderly and very elderly patients with hypertension. Hypertension 2008:22nd Scientific Meeting of the International Society of Hypertension and18th Scientific Meeting of the European Society of Hypertension, 14-19 June 2008. 2008;25.

81. Yarows S, Oparil S, Patel S, Fang H, Zhang J. Aliskiren and valsartan in stage 2 hypertension: Subgroup analysis of a randomized, double-blind study. Adv Ther. 2008;25(12):1288-1302.

82. Yarows SA, Oparil S, Patel S, Arora V, Zhang J. Aliskiren in combination with valsartan provides additional blood pressure-lowering effects compared with either agent alone in elderly and younger patients with hypertension. Hypertension 2008: 22nd Scientific Meeting of the International Society of Hypertension and18th Scientific Meeting of the European Society of Hypertension, 14-19 June 2008. 2008;25.
83. Gradman AH, Weir M, Arora V, Keefe D. Aliskiren provides highly effective blood pressure reduction independent of age in patients with hypertension. American Society of Hypertension Annual Scienftific Meeting and Exposition, May 14-17 2000. J Clin Hypertens. 2008;10: Supplement A.

84. Duprez DA, Davis P, Botha J. Abstract 4423: The AGELESS Study: the effect of aliskiren vs ramipril alone or in combination with hydrochlorothiazide and amlodipinee in patients $\geq 65$ years of age with systolic hypertension. Circulation. 2008;118(18 MeetingAbstracts): S_886-c-887. 
